\title{
Commentary: Biomarkers and magical thinking
}

\author{
Joanna Chikwe, MD, FRCS, and \\ Dominic Emerson, MD
}

If you think the device-driven upheaval in cardiovascular research, practice and business is a big deal, just wait until you see what is happening with biomarkers. Biomarkers encompass almost any aspect of a living organism that you can objectively measure. Described by the US Food and Drug Administration as "a defined characteristic that is measured as an indicator of normal biological processes, pathogenic processes, or responses to an exposure or intervention," biomarkers have been part of medicine from the moment we started measuring pulse rates, ST segments, and serum cholesterol. But we are now on the threshold of explosive growth and change in how we understand, use, and profit from biomarkers, driven by dramatic reductions in the time and cost of measuring an exponentially increasing array of genetic, genomic, and biologic measures; unprecedented capacity to store and analyze vast amounts of data; and major advances in systems biology.

In a superb review, Dr Robert Califf, US Food and Drug Administration commissioner between 2016 and 2017, now affiliated with Stanford, Duke, and Google, underlines the critical importance of biomarkers in discovery science, product development, and health care. He states, "The benefit of using a biomarker for a specific purpose is directly related to the quality of the research supporting it." And there lies the rub. The quality and reproducibility of this research is variable, frequently characterized by misconceptions around the role of biomarkers and the need for rigorous methodology, including validation, with commercial interests dwarfing the cardiovascular devices sector, fueling magical thinking all round.

\footnotetext{
From the Department of Cardiac Surgery, Smidt Heart Institute, Cedars-Sinai Medical Center, Los Angeles, Calif.

Disclosures: Cedars-Sinai Medical Center receives honoraria from EdwardsLifesciences and Medtronic for speaker and consulting activity. Authors have nothing to disclose with regard to commercial support.

Received for publication Oct 22, 2019; revisions received Oct 22, 2019; accepted for publication Oct 23, 2019; available ahead of print Nov 11, 2019.

Address for reprints: Joanna Chikwe, MD, FRCS, Department of Cardiac Surgery, Smidt Heart Institute, Cedars-Sinai Medical Center, 127 S San Vicente Blvd A3600, Los Angeles, CA 90048 (E-mail: Joanna.chikwe@cshs.org).

J Thorac Cardiovasc Surg 2020;160:1247-8 $0022-5223 / \$ 36.00$

Copyright (c) 2020 Published by Elsevier Inc. on behalf of The American Association for Thoracic Surgery

https://doi.org/10.1016/j.jtcvs.2019.10.126
}

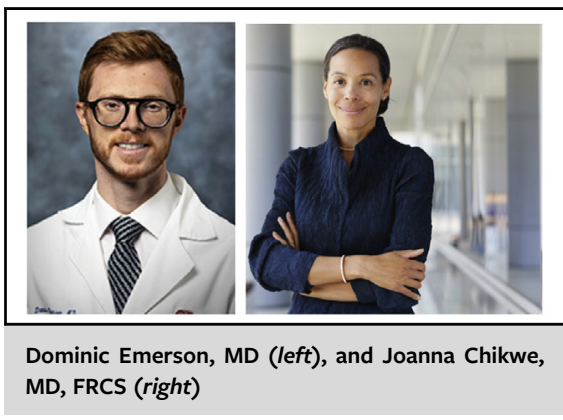

CENTRAL MESSAGE

Novel biomarkers are set to transform science and health care, but rigorous research methodology, including validation, is essential.

Where in this picture of a massive and commercially driven paradigm shift in diagnostics, monitoring, and prediction does the study by Engleman and colleagues ${ }^{2}$ in this issue of the Journal fit? Engleman and colleagues ${ }^{2}$ compared the incidence of postoperative acute kidney injury before and after implementation of a care bundle for patients judged to be at higher risk on the basis of 2 urinary biomarkers. They report reduced rates of kidney injury with their care bundle (which included avoiding nephrotoxic agents, such as angiotensinconverting enzyme inhibitors and contrast; minimizing hyperglycemia; close monitoring of urinary output; and goal-directed fluids) and conclude that routine urinary biomarkers are useful adjuncts, allowing targeted intervention.

The science may be sound, but the logic is faulty. True, some data indicate that these novel biomarkers may be earlier and more reliable markers of postoperative kidney injury than traditional ones, such as oliguria and serum creatinine, but estimates of sensitivity and specificity vary widely, at best approaching $90 \%{ }^{3}$ The study by Engelman and colleagues ${ }^{2}$ really only assesses the efficacy of their renal care bundle. Selecting $50 \%$ of patients at random for this bundle, rather than using biomarkers, might have improved outcomes equally-and treating everyone with the care bundle could have improved outcomes even more. It is impossible to know without relevant comparative data.

This distinction-between the efficacy of the intervention and the utility of the biomarkers-is important. It is important at the patient level, because a fairly standard, safe, and effective care bundle could be withheld from 
almost half of patients on the basis of a test with limited sensitivity and specificity. It is important at the health care level because, citing similarly flawed research, the recent ERAS (Enhanced Recovery After Surgery) guidelines, of which Dr Engleman is lead author, made this use of biomarkers a class IIa recommendation. ${ }^{4}$ And the magic does not stop there- these ERAS guidelines were cited in the 2018 annual report of the $\$ 2.4$ billion revenue biotech company that acquired Astute Medical (who developed this biomarker assay and for whom 3 of the authors consult) for $\$ 90$ million. $^{5}$

\section{References}

1. Califf RM. Biomarker definitions and their applications. Exp Biol Med. 2018;243: 213-21.

2. Engelman DT, Crisafi C, Germain M, Greco B, Nathanson BH, Engelman RM, et al. Using urinary biomarkers to reduce acute kidney injury following cardiac surgery. J Thorac Cardiovasc Surg. 2020;160:1235-46.e2.

3. Finge T, Bertran S, Roger C, Candela D, Pereira B, Scott C, et al. Interest of urinary [TIMP-2] $\times$ [IGFBP-7] for predicting the occurrence of acute kidney injury after cardiac surgery: a gray zone approach. Anesth Analg. 2017;125:762-9.

4. Engelman DT, Ben Ali W, Williams JB, Perrault LP, Reddy VS, Arora RC, et al. Guidelines for perioperative care in cardiac surgery: Enhanced Recovery After Surgery Society recommendations. JAMA Surg. 2019;154:755-66.

5. bioMérieux. 2018 Annual Report; . Available at: https://www.biomerieux.com/ sites/corporate/files/biomerieux_annual_report_2018.pdf. Accessed October 20, 2019.
See Article page 1235 .

\section{Commentary: Is it time for a rapid kidney response team?}

\author{
Richa Dhawan, MD, MPH, and Mark A. Chaney, MD
}

Acute kidney injury (AKI) after cardiac surgery remains a persistent problem, reliably increasing morbidity, hospital length of stay, cost, and mortality. For decades, researchers have tried to tackle the problem of diagnosis and treatment for AKI, with limited success. In this issue of the Journal, Engelman and colleagues, ${ }^{1}$ a group of investigators from Massachusetts, reveal that identification of kidney stress through urinary biomarkers during the immediate postoperative period, followed by initiation of therapeutic interventions, may help.

This retrospective quality improvement project focused on 435 patients before and 412 patients after initiation of an AKI reduction protocol. Patients in the protocol had urinary biomarkers measured the morning after cardiac surgery. If markers were elevated above a predetermined level (indicating kidney stress), a multidisciplinary Acute Kidney Response Team was activated, and they initiated therapeutic interventions according to a predetermined

\footnotetext{
From the Department of Anesthesia and Critical Care, University of Chicago Medical Center, Chicago, Ill.

Disclosures: Authors have nothing to disclose with regard to commercial support.

Received for publication Oct 15, 2019; revisions received Oct 15, 2019; accepted for publication Oct 15, 2019; available ahead of print Oct 31, 2019.

Address for reprints: Richa Dhawan, MD, MPH, Department of Anesthesia and Critical Care, University of Chicago Medical Center, 5841 S Maryland Ave, MC 4028, Chicago, IL 60637 (E-mail: rdhawan@dacc.uchicago.edu).

J Thorac Cardiovasc Surg 2020;160:1248-9

0022-5223/\$36.00

Copyright (c) 2019 by The American Association for Thoracic Surgery

https://doi.org/10.1016/j.jtcvs.2019.10.086
}

Check for updates

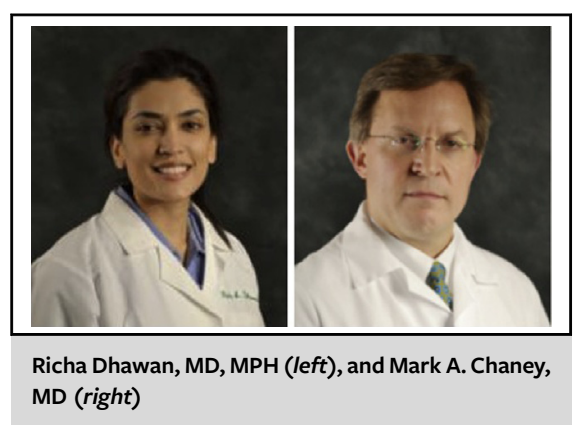

\begin{abstract}
CENTRAL MESSAGE
Identification of postoperative kidney stress through urinary biomarkers, followed by initiation of therapeutic interventions, may decrease incidence of stage 2 to 3 acute kidney injury.
\end{abstract}

algorithm that was based on Kidney Disease: Improving Global Outcomes (KDIGO) guidelines. The Acute Kidney Response Team was activated for $54 \%$ of the 412 patients. Stage 2 to 3 AKI (according to KDIGO criteria) occurred in 10 of 435 control patients (no AKI reduction protocol) yet in only 1 of 412 patients in the intervention group (89\% relative reduction, statistically significant). These results indicate that early intervention and preemptive renal salvage techniques in patients at risk for kidney injury decrease progression to severe AKI.

In clinical practice, AKI is diagnosed on the basis of a decrease in urinary output or increase in serum creatinine, both of which lack sensitivity and specificity. ${ }^{2,3}$ Serum creatinine is a late marker that takes 48 to 72 hours to 